\title{
Influence of Metabolic Syndrome versus Musculoskeletal Disorders on Saudi Health-Related Quality of Life
}

\author{
Salwa B. El-Sobkey ${ }^{*}$, Sahar M. Hassan², Najlaa F. Ewais ${ }^{3}$ \\ ${ }^{1}$ Faculty of Physical Therapy, Modern University for Technology and Information, Cairo, Egypt \\ ${ }^{2}$ Cairo University Educational Hospital, Cairo, Egypt \\ ${ }^{3}$ Faculty of Physical Therapy, Cairo University, Giza, Egypt \\ Email: ${ }^{\text {Salwa-el-sobkey@hotmail.com }}$
}

Received 23 June 2015; accepted 28 July 2015; published 31 July 2015

Copyright (C) 2015 by authors and Scientific Research Publishing Inc.

This work is licensed under the Creative Commons Attribution International License (CC BY).

http://creativecommons.org/licenses/by/4.0/

(c) (i) 0pen Access

\begin{abstract}
Aim: This work aimed to study the influence of two chronic health conditions, metabolic syndrome (MetS) and musculoskeletal disorders (MSDs), on the health-related quality of life (HRQoL) of Saudis. Method: The Medical Outcomes Study Short Form-36 (SF-36) health status questionnaire was used to measure the HRQoL and compare the mean scores of the questionnaire subscales and physical and mental component summaries (PCS and MCS) of 33 patients with MetS, 18 patients with MSDs, and 30 apparently healthy (AH) subjects. Regression analysis was used to measure the prediction power of the study group, age and gender of the participants in estimating the HRQoL. Results: Results showed that the mean scores of the physical subscales, the PCS, the mental subscales and MCS were arranged in descending order from AH subjects, patients with MetS, to patients with MSDs. The mean scores difference among the 3 study groups were statistically significant with the only exception for the general mental health (GMH) subscale $(P=0.404)$. The study group and age accounted for $\mathbf{4 1 . 8 \%}$ of the variability of PCS while the study group accounted for $19.6 \%$ of the variability in the MCS. The resulted equation to estimate the PCS score was as follows: PCS = 113.18 - 12.85 (Group: 0 for AH, 1 for MetS, and 2 for MSDs) - 0.67 age. On the other hand the resulted equation to estimate the MCS score was as follows: MCS $=76.203-10.426$ (Group: 0 for AH, 1 for MetS, and 2 for MSDs). Conclusion: Patients with MetS and patients with MSDs had lower HRQoL than AH subjects. All the physical and mental dimensions of HRQoL are negatively influenced with MetS and with MSDs with the only exception for the GMH subscale. The physical and mental burden of MSDs is more dominant. The study group and age can be used to predict the PCS while the study group can be used to predict the MCS.
\end{abstract}

\footnotetext{
"Corresponding author.
}

How to cite this paper: El-Sobkey, S.B., Hassan, S.M. and Ewais, N.F. (2015) Influence of Metabolic Syndrome versus Musculoskeletal Disorders on Saudi Health-Related Quality of Life. Open Journal of Therapy and Rehabilitation, 3, 87-96. 
Keywords

Saudi Health-Related Quality of Life, Metabolic Syndrome, Musculoskeletal Disorders, Medical
Outcomes Study Short Form-36 (SF-36)

\section{Introduction}

The World Health Organization has extended the definition of health beyond the absence of disease to include the state of complete physical, mental, and social well-being and consequently the healthcare for patients with chronic disease aimed not only to delay death but also to promote health and quality of life [1]-[3]. The healthrelated quality of life (HRQoL) is commonly used to evaluate a patient's subjective sense of physical and mental functioning, and well-being [4]. During the last three decades, the HRQoL has become a significant marker of disease burden and an important outcome of healthcare for patients with chronic diseases [5] [6].

Metabolic syndrome (MetS) is defined as a cluster of metabolic disturbances, including central obesity, hyperglycemia, dyslipidemia and hypertension [7]. The National Cholesterol Education Program expert panel diagnosed the MetS when patients meet at least three of the following 5 criteria: elevated waist circumference ( $>40$ inches for men, $>35$ inches for women); high triglycerides ( $>150 \mathrm{mg} / \mathrm{dl}$ ); reduced high-density lipoprotein cholesterol ( $<40 \mathrm{mg} / \mathrm{dl}$ for men, $<50 \mathrm{mg} / \mathrm{dl}$ for women); high fasting glucose ( $>100 \mathrm{mg} / \mathrm{dl})$; and elevated blood pressure ( $>130 / 85 \mathrm{~mm} \mathrm{Hg})$ [8]. Some investigators claimed that MetS is also associated with an increased risk for psychiatric comorbidity, stress, and impaired HRQoL [9]-[11]. As MetS is considered to be a chronic condition, in recent years, more attention has been paid to the assessment of the impact of MetS on HRQoL [12]-[14]. Diabetes is a worldwide health problem; 387 million people have diabetes in the world and more than 37 million people in the middle east and north Africa region; by 2035 this will rise to 68 million [15]. The prevalence of diabetes is high among the Saudi population (30\%) and represents a major clinical and public health problem [16]. Moreover, in a recent study, $28.7 \%$ of adult Saudis were obese (body mass index $\geq 30 \mathrm{~kg} / \mathrm{m}^{2}$ ) and it was found that obesity remains strongly associated with diabetes, hypercholesterolemia, and hypertension in Saudi Arabia [17]. Components of the MetS including obesity, and hypertension, have been associated with reduced HRQoL, leading some investigators to suggest that MetS itself may also be associated with impaired HRQoL [18].

Meanwhile, musculoskeletal disorders (MSDs) term is used to describe many of joint and/ or muscle conditions including, but not limited to, osteroarthritis, rheumatoid arthritis, back and neck dysfunctions, osteoporosis [19] [20]. The MSDs are painful, usually progressive, chronic conditions and are considered worldwide as major causes to morbidity and have been claimed to have a strong negative influence in terms of HRQoL [19]-[22]. In Saudi Arabia the MSDs are common. For example, the prevalence of osteoarthritis is 30.8\% in those aged 46 55 years and $60.6 \%$ in the age group of 66 - 75 years [23]. On the other hand, back pain was reported in $18.8 \%$ of adult Saudis [24].

The Medical Outcomes Study Short Form-36 (SF-36) health status survey questionnaire is a generic (that is, not disease specific) widely used questionnaire that is used to quantify the HRQoL [20] [25] [26]. It consists of 36 items that are employed to calculate scores on eight dimensions [20]. The physical health subscales include those that measure physical function (PF) (i.e., degree of limitation in performing activities of daily living), physical role (PR) (i.e., limitations in daily activities due to physical health), bodily pain (BP) (i.e., limitations in daily activities due to pain), and general health (GH) (i.e., self evaluation of overall health). The mental health subscales include those that measure vitality (V) (i.e., energy and fatigue), social functioning (SF) (i.e., limitations in social activities due to physical or emotional health), emotional role (ER) (i.e., limitations in usual role activities due to emotional problems), and general mental health (GMH) (i.e., psychological distress and wellbeing) [20] [25]-[27]. For each subscale, scores are ranged from 0 (the worst) to 100 (the best) [20] [27]. Higher score in each subscale and both physical component summary (PCS) and mental component summary (MCS) indicate a better functioning and HRQoL [20] [26] [28]. The current work aimed to study the influence of two chronic conditions, MetS and MSDs, on the HRQoL through comparing the mean scores of SF-36 subscales as well as physical and mental components summaries of patients with MetS and of patients with MSDs with agematched AH subjects. 


\section{Methods}

Patients with MetS and patients with MSDs from the outpatient clinics of King Khaled University Hospital, Riyadh, Saudi Arabia and age-matched AH subjects from Riyadh city community were recruited for this study. All participants signed a consent form and received full explanation for the study aim and procedures. Patients were assured that their participation or not in the study would not affect positively or negatively on their treatment. Convenience study design was used to recruit participants in the three study groups. The first group was the MetS group which included 33 patients who met the MetS definition of National Cholesterol Education Program expert panel [8].

The second group was the MSDs group which included 18 patients with different MSDs as knee osteoarthritis, low back pain and shoulder pain. Patients of these 2 groups were excluded if they had medical or psychiatric comorbidities. The third group was the age-matched AH 30 subjects. All participants were non smokers and are not engaged in any physical activities in regular basis.

The SF-36 questionnaire was introduced to the participants to measure the participants' HRQoL. All participants received clear and complete explanation on how to score its items. One of the researchers was available with the participants during scoring the questionnaire to answer any further queries. The score for each subscale as well as for the physical and mental component summaries were calculated and recorded for each participant of the 3 groups.

\section{Data Analysis}

Data was analyzed using the SPSS version 13.0. Descriptive statistics were used in form of mean and standard deviation for the continuous variable (age) and frequency for the categorical variable (gender). One-way ANOVA was used to compare the mean age of the 3 study groups. It was also used to compare the mean scores of each subscale as well as physical and mental component summaries among the 3 groups. Tukey post hoc test was used to define the difference(s) among the 3 groups in case of significant ANOVA test. Person correlation was used to study the relationships between the scores of subscales and physical and mental component summaries and each of the age, gender, and the study groups. Multiple liner regression was used to measure the prediction power of the age and study groups on estimating the score of physical and mental component summaries. A $\mathrm{P}$ value $<0.05$ was considered significant for all analyses.

\section{Results}

The 81 study participants were aged from 21 to 78 years (mean \pm SD, $55.0 \pm 12.55$ years) (Table 1 ). Their frequency distribution in the 3 study groups was as following; AH group (37.0\%), with MetS group (40.7\%), and with MSDs group (22.2\%). There was no statistical difference $(\mathrm{P}=0.711)$ among the 3 groups age means.

As shown in Figure 1(a) and Figure 1(b), the mean scores of the physical subscales, the PCS, the mental subscales and MCS were arranged in descending order from AH subjects, patients with MetS, to patients with MSDs. The mean scores difference among the 3 study groups were statistically significant with the only exception for the GMH subscale $(\mathrm{P}=0.404)$. Multiple comparisons in Table 2 indicated that the AH subjects had

Table 1. Baseline characteristics of participants with metabolic syndrome, musculoskeletal disorders, and apparently healthy.

\begin{tabular}{|c|c|c|c|c|c|c|}
\hline & & & AH & With MetS & With MSDs & Total \\
\hline \multirow{4}{*}{ Age } & \multicolumn{2}{|c|}{ Minimum } & 39 & 32 & 21 & 21 \\
\hline & \multicolumn{2}{|c|}{ Maximum } & 75 & 78 & 73 & 78 \\
\hline & \multicolumn{2}{|c|}{ Mean } & 53.6 & 56.2 & 55.0 & 55.0 \\
\hline & \multicolumn{2}{|c|}{ SD } & 10.70 & 12.76 & 15.28 & 12.55 \\
\hline \multirow{3}{*}{ Gender } & Female & N (\%) & $12(40.0 \%)$ & 17 (42.4\%) & $9(50.0 \%)$ & 38 (46.9\%) \\
\hline & Male & N (\%) & $18(60.0 \%)$ & $16(48.6 \%)$ & $9(50.0 \%)$ & $43(53.1 \%)$ \\
\hline & Total & N (\%) & 30 (37.0\%) & 33 (40.7\%) & $18(22.2 \%)$ & $81(100.0 \%)$ \\
\hline
\end{tabular}

Apparently Healthy (AP), Metabolic Syndrome (MetS), Musculoskeletal Disorders (MSDs). 
Table 2. Multiple comparisons of SF-36 health related quality of life mean scores of physical subscales and physical component summary among participants with metabolic syndrome, musculoskeletal disorders, and apparently healthy.

\begin{tabular}{|c|c|c|c|c|}
\hline Subscale & (I) group & (J) group & Mean Difference (I-J) & $P$ value \\
\hline \multirow{3}{*}{$\mathrm{PF}$} & $\mathrm{AH}$ & MetS & 11.44 & 0.113 \\
\hline & & MSDs & $20.56\left({ }^{*}\right)$ & 0.008 \\
\hline & MetS & MSDs & 9.1162 & 0.351 \\
\hline \multirow{3}{*}{ PR } & $\mathrm{AH}$ & MetS & $29.09\left({ }^{*}\right)$ & 0.001 \\
\hline & & MSDs & $50.278\left(^{*}\right)$ & 0.000 \\
\hline & MetS & MSDs & 21.19 & 0.055 \\
\hline \multirow{3}{*}{$\mathrm{BP}$} & $\mathrm{AH}$ & MetS & $13.24\left({ }^{*}\right)$ & 0.026 \\
\hline & & MSDs & $23.08\left({ }^{*}\right)$ & 0.001 \\
\hline & MetS & MSDs & 9.8485 & 0.212 \\
\hline \multirow{3}{*}{ GH } & $\mathrm{AH}$ & MetS & 3.87 & 0.589 \\
\hline & & MSDs & $12.86\left(^{*}\right)$ & 0.019 \\
\hline & MetS & MSDs & 8.99 & 0.127 \\
\hline \multirow{3}{*}{ PCS } & $\mathrm{AH}$ & MetS & $15.43\left(^{*}\right)$ & 0.006 \\
\hline & & MSDs & $27.94\left(^{*}\right)$ & 0.0001 \\
\hline & MetS & MSDs & 12.51 & 0.071 \\
\hline
\end{tabular}

Physical Function (PF), Physical Role (PR), Bodily Pain (BP), General Health (GH), Physical Component Summary (PCS), Apparently Healthy (AP), Metabolic Syndrome (MetS), Musculoskeletal Disorders (MSDs). ${ }^{*}$ The mean difference is significant at the 0.05 level.

higher significant mean score of PCS than patients with MetS $(\mathrm{P}=0.006)$ and higher significant mean score than patients with MSDs $(\mathrm{P}=0.0001)$. Meanwhile patients with MetS had higher mean score than patients with MSDs but without significant difference $(\mathrm{P}=0.071)$.

Multiple comparisons in Table 2 indicated that the AH subjects had higher significant mean scores than patients with MSDs for all physical subscales. While the AH subjects had higher significant mean scores than patients with MetS for only PR $(\mathrm{P}=0.001)$ and $\mathrm{BP}(\mathrm{P}=0.026)$. For the PCS, AH subjects had higher significant mean score than patients with MetS $(\mathrm{P}=0.006)$ and higher significant mean score than patients with MSDs $(\mathrm{P}=$ 0.0001). Meanwhile patients with MetS had higher mean score than patients with MSDs but without significant difference $(\mathrm{P}=0.071)$.

Multiple comparisons in Table 3 showed that AH subjects had higher significant mean scores than patients with MSDs for ER, V, and SF mental subscales and had higher significant mean scores than patients with MetS for SF mental subscale. The mental subscales that showed significant higher mean scores for MetS patients than MSDs were the ER and V. For the MCS, both AH subjects and patients with MetS had higher significant mean score than patients with MSDs ( $\mathrm{P}=0.0001$, and 0.038 respectively).

Two-tailed person correlations (Table 4) showed that participant's study group had negative correlation with the all the physical and mental subscales and component summaries. The higher the group category code $\mathrm{AH}=$ 0 , with MetS $=1$, and with MSDs $=2$ ), the lower the mean score. The GMH subscale was the only excluded subscale from this phenomenon $(\mathrm{P}=0.179)$. Age was correlated more to the physical subscales and PCS than to the mental subscales and MCS. On the other hand, gender had no correlation neither with the physical and mental subscales nor their component summaries.

Regression analysis (Table 5(a) and Table 5(b)) showed that the study group accounted for $25.1 \%$ of the variability in the PCS while both study group and age accounted for $41.8 \%$ of the variability. Meanwhile the study group accounted for $19.6 \%$ of the variability in the MCS. The resulted equation to estimate the PCS score was as following; PCS = 113.18 - 12.85 (Group: 0 for AH, 1 for MetS, and 2 for MSDs) - 0.67 age. On the other hand the resulted equation to estimate the MCS score was as following; MCS $=76.203-10.426$ (Group: 0 for AH, 1 for MetS, and 2 for MSDs). 


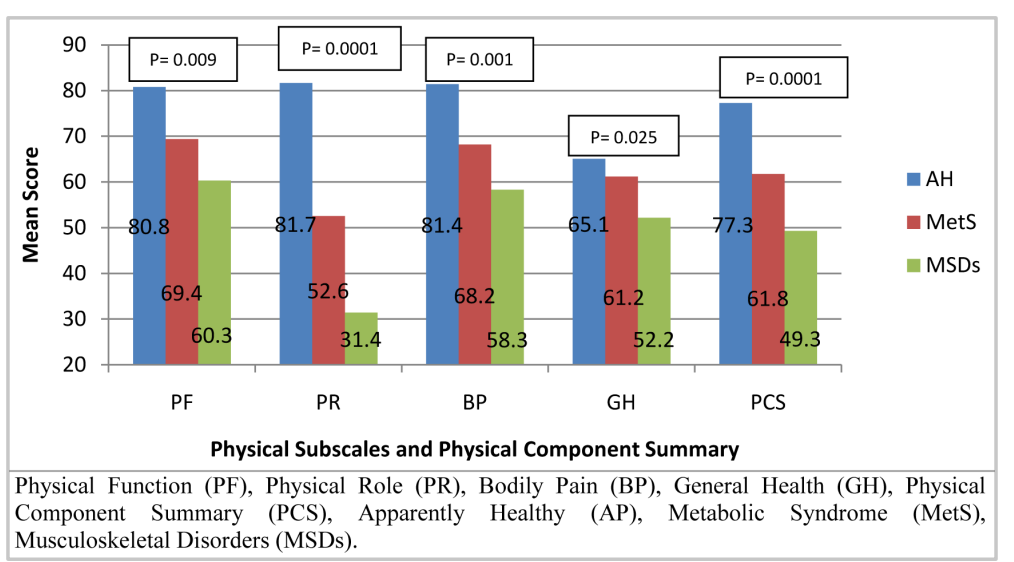

(a)

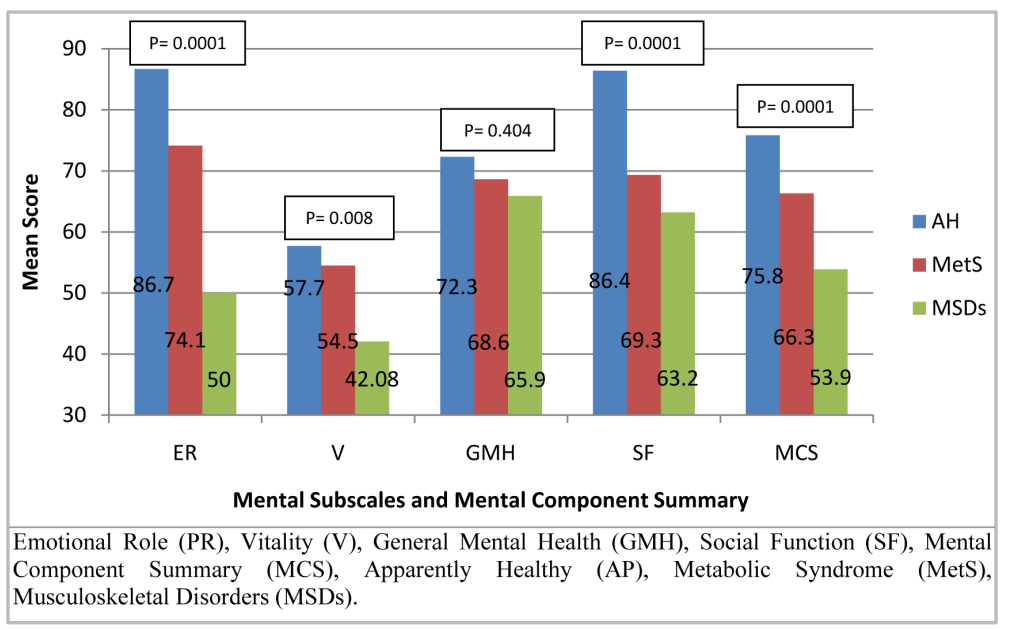

(b)

Figure 1. (a). The SF-36 health related quality of life mean scores of physical subscales and physical component summary among participants with metabolic syndrome $(\mathrm{N}=33)$, musculoskeletal disorders $(\mathrm{N}=18)$, and apparently healthy $(\mathrm{N}=30)$; (b) The SF-36 health related quality of life mean scores of mental subscales and mental component summary among participants with metabolic syndrome $(\mathrm{N}=33)$, musculoskeletal disorders $(\mathrm{N}=18)$, and apparently healthy $(\mathrm{N}=30)$.

\section{Discussion}

Reduction of patients' signs and symptoms along with the improvement in their medical investigations' results are no longer the only outcomes for health care. The HRQoL became an integral element of health care outcomes and its importance is progressively increased. Patients' perceptions regarding their HRQoL are commonly used to monitor the prognosis of their health conditions especially with chronic diseases and disorders. With the drift of the Saudi community toward modernization, stresses and sedentary life style resulted in health problems such as hypertension and obesity which caused chronic health conditions as MetS and MSDs. Because it is known that chronic health conditions are associated with impaired HRQoL [25], the current work aimed to study the influence of these two chronic conditions, MetS and MSDs, on the HRQoL. To do so, the mean scores of SF-36 subscales as well as physical and mental components summaries of patients with MetS and of patients with MSDs were compared with age-matched AH subjects.

In the current study patients with MetS and patients with MSDs had lesser HRQoL than the AH subjects as they had lower mean scores in all subscales, PCS, and MCS of the SF-36 questionnaire. The lower mean scores recorded for patients with MetS and patients with MSDs were significant with the only exception for GMH 
Table 3. Multiple comparisons of SF-36 health related quality of life mean scores of mental subscales and mental component summary among participants with metabolic syndrome, musculoskeletal disorders, and apparently healthy.

\begin{tabular}{ccccc}
\hline Subscale & (I) group & (J) group & Mean Difference (I-J) & P value \\
\hline \multirow{2}{*}{ ER } & AH & MetS & 12.53 & 0.219 \\
& MSDs & MSDs & $36.66\left(^{*}\right)$ & 0.000 \\
& AH & MetS & $24.13\left(^{*}\right)$ & 0.018 \\
V & MSDs & 3.18 & 0.734 \\
& MetS & MSDs & $15.60\left(^{*}\right)$ & 0.007 \\
AH & MetS & $12.42\left(^{*}\right)$ & 0.035 \\
& MSDs & MSDs & 3.66 & 0.645 \\
& MetS & MetS & 6.32 & 0.396 \\
& AH & MSDs & 2.66 & 0.842 \\
& MetS & MSDs & $17.09\left(^{*}\right)$ & 0.005 \\
& AH & MetS & $23.22\left(^{*}\right)$ & 0.001 \\
& MSDs & MSDs & 6.13 & 0.582 \\
\end{tabular}

Emotional Role (PR), Vitality (V), General Mental Health (GMH), Social Function (SF), Mental Component Summary (MCS), Apparently Healthy (AP), Metabolic Syndrome (MetS), Musculoskeletal Disorders (MSDs). ${ }^{*}$ The mean difference is significant at the .05 level.

Table 4. Person correlations between participants characteristics (study groups: apparently healthy, with metabolic syndrome, with musculoskeletal disorders, gender, and age) and the mean scores of both physical and mental subscales and component summaries.

\begin{tabular}{|c|c|c|c|c|c|c|c|c|c|}
\hline & & Group & Gender & Age & PF & PR & BP & GH & PCS \\
\hline \multirow[t]{3}{*}{ Group } & $\mathbf{r}$ & 1 & -0.086 & 0.055 & $-0.337\left(^{* *}\right)$ & $-0.538\left(^{* *}\right)$ & $-0.415\left(^{* *}\right)$ & $-0.290\left(^{* *}\right)$ & $-0.500\left(^{* *}\right)$ \\
\hline & Sig. & & 0.445 & 0.627 & 0.002 & 0.0001 & 0.0001 & 0.009 & 0.0001 \\
\hline & $\mathbf{N}$ & & 81 & 81 & 81 & 81 & 81 & 81 & 81 \\
\hline \multirow[t]{3}{*}{ Gender } & $\mathbf{r}$ & & 1 & 0.080 & -0.036 & 0.213 & 0.207 & -0.008 & 0.136 \\
\hline & Sig. & & & 0.476 & 0.749 & 0.057 & 0.063 & 0.942 & 0.225 \\
\hline & $\mathbf{N}$ & & & 81 & 81 & 81 & 81 & 81 & 81 \\
\hline \multirow[t]{4}{*}{ Age } & $\mathbf{r}$ & & & 1 & $-0.529\left(^{* *}\right)$ & $-0.351\left(^{* *}\right)$ & $-0.392\left(^{* *}\right)$ & -0.136 & $-0.437\left(^{* *}\right)$ \\
\hline & Sig. & & & & 0.0001 & 0.001 & 0.0001 & 0.227 & 0.0001 \\
\hline & $\mathbf{N}$ & & & & 81 & 81 & 81 & 81 & 81 \\
\hline & & Group & Gender & Age & ER & $\mathbf{V}$ & GMH & SF & MCS \\
\hline \multirow[t]{3}{*}{ Group } & $\mathbf{r}$ & 1 & -0.086 & 0.055 & $-0.422\left(^{* *}\right)$ & $-0.316\left(^{* *}\right)$ & -0.151 & $-0.405\left(^{* *}\right)$ & $-0.442\left(^{* *}\right)$ \\
\hline & Sig. & & 0.445 & 0.627 & 0.0001 & 0.004 & 0.179 & 0.0001 & 0.0001 \\
\hline & $\mathbf{N}$ & & 81 & 81 & 81 & 81 & 81 & 81 & 81 \\
\hline \multirow[t]{3}{*}{ Gender } & $\mathbf{r}$ & & 1 & 0.080 & 0.169 & 0.164 & -0.032 & -0.111 & 0.078 \\
\hline & Sig. & & & 0.476 & 0.132 & 0.143 & 0.776 & 0.324 & 0.489 \\
\hline & $\mathbf{N}$ & & & 81 & 81 & 81 & 81 & 81 & 81 \\
\hline \multirow[t]{3}{*}{ Age } & $\mathbf{r}$ & & & 1 & $-0.270\left(^{*}\right)$ & -0.038 & 0.120 & $-0.226\left(^{*}\right)$ & -0.183 \\
\hline & Sig. & & & & 0.015 & 0.738 & 0.287 & 0.043 & 0.103 \\
\hline & $\mathbf{N}$ & & & & 81 & 81 & 81 & 81 & 81 \\
\hline
\end{tabular}

Physical Function (PF), Physical Role (PR), Bodily Pain (BP), General Health (GH), Physical Component Summary (PCS), Emotional Role (PR), Vitality (V), General Mental Health (GMH), Social Function (SF), Mental Component Summary (MCS). ${ }^{* *}$ Correlation is significant at the 0.01 level (2-tailed). ${ }^{*}$ Correlation is significant at the 0.05 level (2-tailed). 
Table 5. Prediction power of study group and age on estimating the score of physical (a) and mental (b) component summaries of participants' quality of life.

\begin{tabular}{|c|c|c|c|c|c|c|c|}
\hline \multicolumn{4}{|c|}{ (a) } & \multicolumn{4}{|c|}{ (b) } \\
\hline & B & SE B & $\beta$ & & B & SE B & $\boldsymbol{\beta}$ \\
\hline Step 1 & & & & Step 1 & & & \\
\hline Constant & 76.91 & 2.98 & & Constant & 76.20 & 2.71 & \\
\hline Study Group & -13.46 & 2.62 & $-0.50^{*}$ & Study Group & -10.43 & 2.38 & $-0.44^{*}$ \\
\hline \multicolumn{8}{|l|}{ Step 2} \\
\hline Constant & 113.18 & 8.08 & & & & & \\
\hline Study Group & -12.85 & 2.33 & $-0.48^{*}$ & & & & \\
\hline Age & -0.67 & 0.14 & $-0.41^{*}$ & & & & \\
\hline
\end{tabular}

(a) $\mathrm{R}^{2}=0.25$ for step $1 ; \mathrm{R}^{2}=0.16$ for step $2 .{ }^{*}$ Regression is significant at the 0.05 level. (b) $\mathrm{R}^{2}=0.19$ for step. ${ }^{*}$ Regression is significant at the 0.05 level.

subscale. This result is fair logic. The MetS can result in limitation of performing the daily activity due to obesity and due to complication of hyperglycemia as muscle weakness and low body energy. Bodily pain can be resulted from headache of hypertension. Those physical limitations can negatively affect the patients' vitality and limit their social function. The same is applied for patients with MSDs who are known to be accompanied with sever bodily pain and limitation of physical activities that interferes with day to day activities and that can burden the social function and reduce the patients' perceptions to their vitality. Although the GMH mean scores were lower in patients with MetS and in patients with MSDs than the AH subjects, this lower scores did not show statistical significance. This result can be explained through the coping strategies. Coping strategies is the effective use of mechanisms by which people respond to and manage stress [29]. Patients with chronic health conditions develop cognitive and behavioral strategies to adapt to their health conditions. Eldred (2011) stated that living with chronic illness requires the ability to adapt to living with the stressors such as pain and fatigue [29]. One of these coping strategies is the spiritual coping mechanisms. Narayanasamy (2002) claimed that chronic illness led patients to use the following spiritual coping mechanisms: faith, prayer, and related sources of support [30]. These spiritual coping mechanisms are perfectly matching with the Islamic culture of the Saudis. Faith and satisfaction with destiny, including poor health conditions, may allow internal self peace and reduce the disease mental burden and preserve the reduction in GMH subscale from being so marked. So even with chronic health problems and lesser HRQoL, Saudi patients are protected from significant psychological stresses and safe their perceptions of well being by the above mentioned spiritual coping mechanism and Islamic concepts. Lower HRQoL in patients with MetS and in patients with MSDs is also reported in many previous studies [11] [19]-[22] [25] [31] and preservation of GMH dimension is also recorded in similar study applied on Australian population [25].

The multiple comparisons with post hoc test provided more detailed picture about the influence of the MetS and MSDs on physical health of patients. For patients with MSDs, all the physical subscales had significant lower mean scores than those for the AH subjects. The condition is different for patients with MetS as only the PR and BP subscales showed lower significant mean scores than the mean scores for AH subjects. In addition, there were no significant difference in any of the physical subscales between patients with MSDs and patients with MetS. These results can indicate that the physical burden is more dominant in patients with MSDs than in patients with MetS. This phenomenon support the claim of Picavet (2004) that compared with other chronic diseases, patients with musculoskeletal disorders usually report the lowest HRQoL [20]. Other previous studies [19] [22] also highlighted the negative impact of physical health and pain on the physical dimension of HRQoL for patients with MSDs and it was so fair to imagine how the locomotor system, musculoskeletal system, disorders can limit the physical function through mechanical changes and bodily pain. The current study raises the physical limitation dimension to one of the internal medicine health condition, MetS.

It was observed that patients with MSDs not only had the lowest physical health dimension of HRQoL but also the lowest mental health dimension. Excluding the GMH already discussed previously, patients with MSDs 
had lower significant means scores than the AH subjects for all mental subscales. The MSDs resulted in mechanical changes and pain making any usual physical activity requiring more energy to be conducted. This explanation gives reason for lower vitality and energy perceived by patients with MSDs. Again with limited physical health, patients with MSDs can have difficulty to participate normally in daily activities including the social activities and functions. The MCS for patients with MSDs figured out their dramatic situation as they are not only having lower mean score than the AH subjects but also they have significant lower mean score than patients MetS. Higher burden of physical limitation for patients with MSDs is translated into higher mental burden.

Although the situation of mental dimension of HRQoL for patients with MetS is better than those with MSDs, the condition is not totally free. Patients with MetS had significant lower scores than the AH subjects in the SF subscale. The SF is defined as the limitations in social activities due to physical or emotional health [20] [25]-[27]. The physical limitation for MetS was discussed earlier. The obesity with its affection on the subject cosmetic look, the hypertension and high blood glucose level with the patients needs to conduct endless times of measurement and to subject to the stress of if the measurements outcomes are controlled or not can markedly negatively affect the MetS patients emotional health.

To go further in the study, researchers studied the relationship between the HRQoL subscales and each of the following factors; study group (AH, MetS, MSDs), age and gender. The study group was positively correlated to all physical and mental subscales as well as to the PCS and MCS with the only exception for GMH. Going from $\mathrm{AH}$, to patients with MetS, to patients with MSDs the mean scores are getting worse. Age also showed some sort of negative relationships with the subscales and component summaries of the HRQoL, The older the age, the lower the mean scores. On the other hand gender showed no relation at all with any of the studied subscales.

Factors that showed relationship with HRQoL (study group and age) were more studied in depth to measure their prediction power to the Saudi HRQoL particularly the PCS and MCS. It was interesting to find that the study group and age predicted $41.8 \%$ of the PCS variability while only the study group predicted $19.6 \%$ of the variability in the MCS. Age was included in the prediction equation of PCS while it was excluded from the prediction equation of MSC. Actually with aging people subject to age related changes that include both physical and mental changes. It would be speculated that age would be included in the prediction equation for both the physical and mental component, but the spiritual cooping strategies and Islamic culture we been discussing formerly may preserve the Saudis mental health even with getting old.

\section{Conclusion}

Chronic health conditions as MetS and MSDs negatively influence the Saudi HRQoL. Patients with MetS and patients with MSDs had lower mean scores than the AH subjects for all physical and mental subscales of SF-36. They also had lower mean scores for PCS and MCS. Patients with MSDs had more physical and mental disease burden than patients with MetS.

\section{Clinical Implication}

Plan of care for patients with MetS must consider the physical health burden of the disease. Assessment and rehabilitation to the locomotor system must be included for patients with MetS. Likely, the mental distress caused by the MSDs should be accounted during their rehabilitation plan of care.

\section{Recommendations}

There is crucial need to determine the norm of HRQoL for Saudis and Arab populations so that future works can study the influence of different chronic diseases on the HRQoL through comparing with the norms mean scores of different HRQoL subscales.

\section{References}

[1] Muldoon, M.F., Barger, S.D., Flory, J.D. and Manuck, S.B. (1998) What Are Quality of Life Measurements Measuring? BMJ, 316, 542-545. http://dx.doi.org/10.1136/bmj.316.7130.542

[2] Guyatt, G.H., Feeny, D.H. and Patrick, D.L. (1993) Measuring Health-Related Quality of Life. Annals of Internal Medicine, 118, 622-629. http://dx.doi.org/10.7326/0003-4819-118-8-199304150-00009 
[3] Breslow, L. (1972) A Quantitative Approach to the World Health Organization Definition of Health: Physical, Mental and Social Well-Being. International Journal of Epidemiology, 1, 347-355. http://dx.doi.org/10.1093/ije/1.4.347

[4] Kalantar, Z.K. and Unruh, M. (2005) Health Related Quality of Life in Patients with Chronic Kidney Disease. International Urology and Nephrology, 37, 367-378. http://dx.doi.org/10.1007/s11255-004-0012-4

[5] Lopes, A.A., Bragg-Gresham, J.L., Satayathum, S., McCullough, K., Pifer, T., Goodkin, D.A., Mapes, D.L., Young, E.W., Wolfe, R.A., Held, P.J. and Port, F.K. (2003) Health Related Quality of Life and Associated Outcomes among Hemodialysis Patients of Different Ethnicities in the United States: The Dialysis Outcomes and Practice Patterns Study (DOPPS). American Journal of Kidney Diseases, 41, 605-615. http://dx.doi.org/10.1053/ajkd.2003.50122

[6] Lam, C.L. and Lauder, I.J. (2000) The Impact of Chronic Diseases on the Health-Related Quality of Life (HRQOL) of Chinese Patients in Primary Care. Family Practice, 17, 159-166. http://dx.doi.org/10.1093/fampra/17.2.159

[7] Grundy, S.M., Cleeman, J.I., Daniels, S.R., Donato, K.A., Eckel, R.H., Franklin, B.A., Gordon, D.J., Krauss, R.M., Savage, P.J., Smith Jr, S.C., Spertus, J.A. and Costa, F. (2005) Diagnosis and Management of the Metabolic Syndrome: An American Heart Association/National Heart, Lung, and Blood Institute Scientific Statement: Executive Summary. Critical Pathways in Cardiology, 4, 198-203. http://dx.doi.org/10.1097/00132577-200512000-00018

[8] Expert Panel on Detection and Treatment of High Blood Cholesterol in Adults (2001) Executive Summary of the Third Report of the National Cholesterol Education Program (NCEP) Expert Panel on Detection, Evaluation, and Treatment of High Blood Cholesterol in Adults (Adult Treatment Panel III). JAMA, 285, 2486-2497. http://dx.doi.org/10.1001/jama.285.19.2486

[9] Duclos, M., Pereira, M.P., Barat, P., Gatta, B. and Roger, P. (2005) Increased Cortisol Bioavailability, Abdominal Obesity, and the Metabolic Syndrome in Obese Women. Obesity Research, 13, 1157-1166. http://dx.doi.org/10.1038/oby.2005.137

[10] Bjorntorp, P. (2001) Do Stress Reactions Cause Abdominal Obesity and Comorbidities? Obesity Reviews, 2, 73-86. http://dx.doi.org/10.1046/j.1467-789x.2001.00027.x

[11] Lidfeldt, J., Nyberg, P., Nerbrand, C., Samsioe, G., Schersten, B. and Aqardh, C.D. (2003) Socio-Demographic and Psychosocial Factors Are Associated with Features of the Metabolic Syndrome. The Women's Health in the Lund Area (WHILA) Study. Diabetes, Obesity and Metabolism, 5, 106-112. http://dx.doi.org/10.1046/j.1463-1326.2003.00250.x

[12] Roriz-Cruz, M., Rosset, I., Wada, T., Sakagami, T., Ishine, M., Roriz-Filho, J.S., Cruz, T.R., Rodrigues, R.P., Resmini, I., Sudoh, S., Wakatsuki, Y., Nakagawa, M., Souza, A.C., Kita, T. and Matsubayashi, K. (2007) Stroke-Independent Association between Metabolic Syndrome and Functional Dependence, Depression, and Low Quality of Life in Elderly Community-Dwelling Brazilian People. Journal of the American Geriatrics Society, 55, 374-382. http://dx.doi.org/10.1111/j.1532-5415.2007.01068.x

[13] Chedraui, P., Hidalgo, L., Chavez, D., Morocho, N., Alvarado, M. and Huc, A. (2007) Quality of Life among Postmenopausal Ecuadorian Women Participating in a Metabolic Syndrome Screening Program. Maturitas, 56, 45-53. http://dx.doi.org/10.1016/j.maturitas.2006.05.008

[14] Ford, E.S. and Li, C. (2008) Metabolic Syndrome and Health-Related Quality of Life among US Adults. Annals of Epidemiology, 18, 165-171. http://dx.doi.org/10.1016/j.annepidem.2007.10.009

[15] International Diabetes Federation, Middle East and North Africa. Saudi Arabia Is One of the 20 Countries of the IDF MENA Region. http://www.idf.org/membership/mena/saudi-arabia

[16] Alqurashi, K.A., Aljabri, K.S. and Bokhari, S.A. (2011) Prevalence of Diabetes Mellitus in a Saudi Community. Annals of Saudi Medicine, 31, 19-23. http://dx.doi.org/10.4103/0256-4947.75773

[17] Memish, Z.A., El Bcheraoui, C., Tuffaha, M., Robinson, M., Daoud, F., Jaber, S., Mikhitarian, S., Al Saeedi, M., AlMazroa, M.A., Mokdad, A.H. and Al Rabeeah, A.A. (2014) Obesity and Associated Factors-Kingdom of Saudi Arabia, 2013. Preventing Chronic Disease, 11, Article ID: 140236. http://dx.doi.org/10.5888/pcd11.140236

[18] Vetter, M.L., Wadden, T.A., Lavenberg, J., Moore, R.H., Volger, S., Perez, J.L., Sarwer, D.B. and Tsai, A.G. (2011) Relation of Health-Related Quality of Life to Metabolic Syndrome, Obesity, Depression, and Comorbid Illnesses. International Journal of Obesity, 35, 1087-1094. http://dx.doi.org/10.1038/ijo.2010.230

[19] Mili, F., Helmick, C.G. and Moriarty, D.G. (2003) Health Related Quality of Life among Adults Reporting Arthritis: Analysis of Data from the Behavioral Risk Factor Surveillance System, US, 1996-99. Journal of Rheumatology, 30, 160-166.

[20] Picavet, H.S.J. and Hoeymans, N. (2004) Health Related Quality of Life in Multiple Musculoskeletal Diseases: SF-36 and EQ-5D in the DMC3 Study. Annals of the Rheumatic Diseases, 63, 723-729. http://dx.doi.org/10.1136/ard.2003.010769

[21] Arvidsson, S., Arvidsson, B., Fridlund, B. and Bergman, S. (2008) Health Predicting Factors in a General Population over an Eight-Year Period in Subjects with and without Chronic Musculoskeletal Pain. Health and Quality of Life Outcomes, 6, 98. http://dx.doi.org/10.1186/1477-7525-6-98 
[22] Woolf, A.D. (2000) The Bone and Joint Decade 2000-2010. Annals of the Rheumatic Diseases, 59, 81-82. http://dx.doi.org/10.1136/ard.59.2.81

[23] Al-Arfaj, A.S., Alballa, S.R., Al-Saleh, S.S., Al-Dalaan, A.M., Bahabry, S.A., Mousa, M.A. and Al-Sekeit, M.A. (2003) Knee Osteoarthritis in Al-Qaseem, Saudi Arabia. Saudi Medical Journal, 24, 291-293.

[24] Al-Arfaj, A.S., Al-Saleh, S.S., Alballa, S.R., Al-Dalaan, A.N., Bahabri, S.A., Al-Sekeit, M.A. and Mousa, M.A. (2003) How Common Is Back Pain in Al-Qaseem Region. Saudi Medical Journal, 24, 170-173.

[25] Montgomerie, A., Chittleborough, C., Taylor, A., Phillips, P.J., Adams, R., Ruffin, R.E. and Wilson, D.H., the North West Adelaide Health Study Team (2010) The Relationship between Metabolic Syndrome and Health Related Quality of Life-Results from the North West Adelaide Health Study. Alicia Montgomerie BHSc, Epidemiological Research Officer, Population Research \& Outcome Studies, Health Intelligence, Department of Health Government of South Australia. https://health.adelaide.edu.au/pros/docs/presentations/Rship_met_syndrome_and_health_related_QOL.pdf

[26] Ware Jr., J.E. and Gandek, B. (1998) Overview of the SF-36 Health Survey and the International Quality of Life Assessment (IQOLA) Project. Journal of Clinical Epidemiology, 51, 903-912. http://dx.doi.org/10.1016/S0895-4356(98)00081-X

[27] Tsai, A.G., Wadden, T.A., Sarwer, D.B., Berkowitz, R.I., Womble, L.G., Hesson, L.A., Phelan, S. and Rothman, R. (2008) Metabolic Syndrome and Health-related Quality of Life in Obese Individuals Seeking Weight Reduction. Obesity, 16, 59-63. http://dx.doi.org/10.1038/oby.2007.8

[28] Amiri, P., Hosseinpanah, F., Jalali-Farahani, S., Mehrabi, Y., Montazeri, A. and Azizi, F. (2014) Is Persistence of Metabolic Syndrome Associated with Poor Health-Related Quality of Life in Non-Diabetic Iranian Adults? Tehran Lipid and Glucose Study. Journal of Diabetes Investigation, 5, 687-693. http://dx.doi.org/10.1111/jdi.12222

[29] Eldred, K.T. (2011) Coping with Chronic Illness: Do Strategies Differ by Illness Type? UNF Theses and Dissertations, Paper 125. http://digitalcommons.unf.edu/etd/125

[30] Narayanasamy, A. (2002) Spiritual Coping Mechanisms in Chronically Ill Patients. British Journal of Nursing, 11, 1461-1470.

[31] Sullivan, P.W., Ghushchyan, V., Wyatt, H.R., Wu, E.Q. and Hill, J.O. (2007) Impact of Cardiometabolic Risk Factor Clusters on Health-Related Quality of Life in the US. Obesity, 15, 511-521. http://dx.doi.org/10.1038/oby.2007.580 